\title{
網系の腐蝕に関する微生物学的研究一跴 海水性好気性繊維素分解菌の纖維素分解機棈について
}

\author{
門田元 \\ (京都大学眎学部水虐微生物学研究意)
Microbiological Studies on the Weakening of Netting Cords-II
On the Mode of Cellulose-Degradation by the Marine
Aerobic Cellulose-Decomposing Bacteria.
Hajime KaDOTA

The mode of cellulose-degradation by the marine a robic cellulose-decomposing bacteria ( $V i$ brio purpureus, Vibrio purpureus var. albus and Cellvibrio flavescens var. marinus) was studied by observing the changes in weight, copper numbr and index ( $R$ ) os ridual cellulose.

The results obtained indicate that there are distinct differences acoong the modes of cellulose-decoroposition by the organisms employed. It is thought that the roode of attack of cellulose by Vibrio purpureus and Vibrio purpureus var. albus is "weathering" type and that of Cellvibrio flavescens var. marinus "liquefying" type.

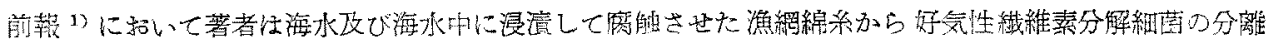

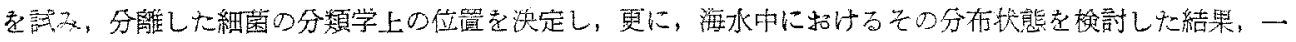

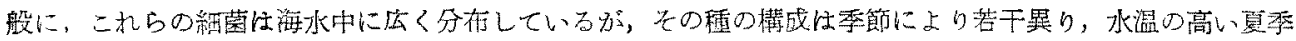

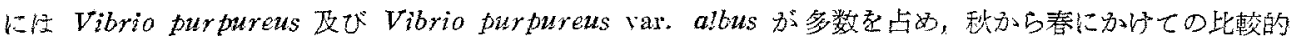

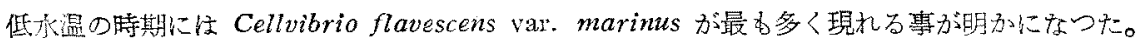

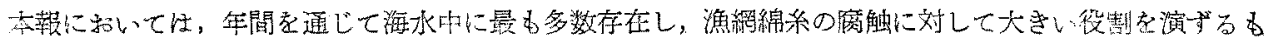

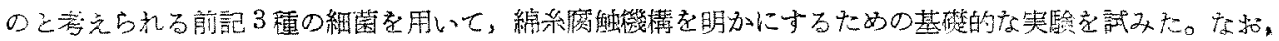

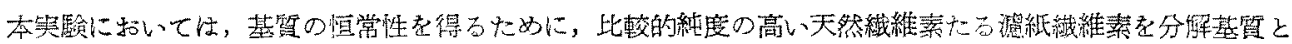
して集用した。

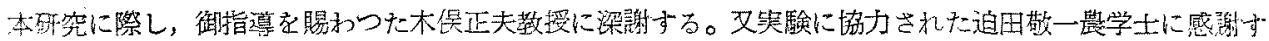
\$o

㵶維营の水溶性化

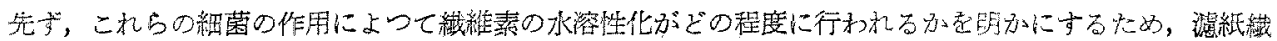

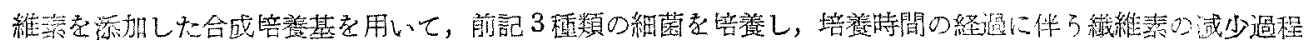
老嚄察した。

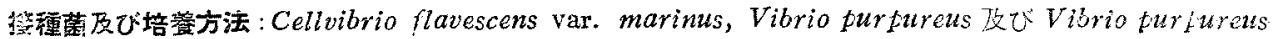

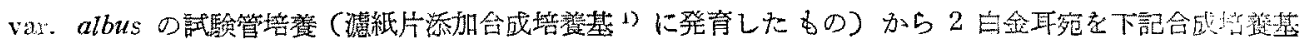

1952 年 4 月 10 日受理

*. 交部省科学研究費による。 


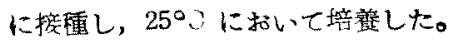

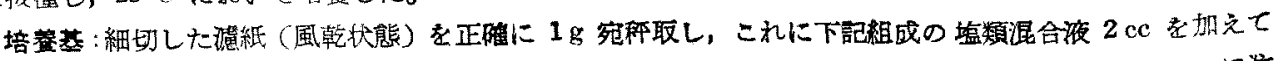

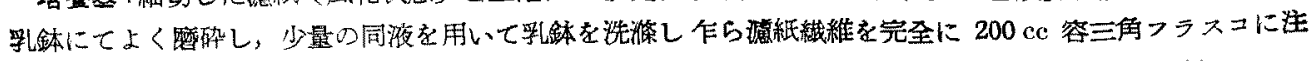

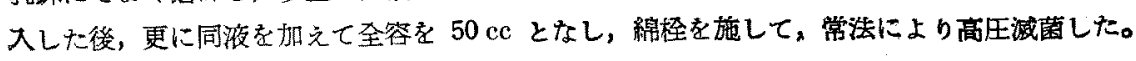

醏類混合渮*の組成は次の如くであ。

\begin{tabular}{|c|c|}
\hline $\mathrm{NaNO}$ & $0.5 \mathrm{~g}$ \\
\hline $\mathrm{K}_{2} \mathrm{HPO}_{4}$ & 1.0 \\
\hline $\mathrm{MgSO} \cdot \cdot 7 \mathrm{H}_{2} \mathrm{O}$ & 0.5 \\
\hline $\mathrm{FeSO} \cdot 7 \mathrm{H}_{2} \mathrm{O}$ & 0.01 \\
\hline 濾過海水 & 1000.0 \\
\hline
\end{tabular}

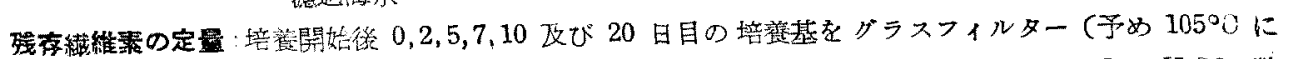

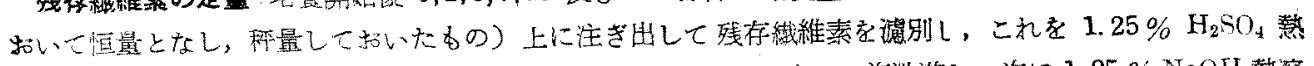

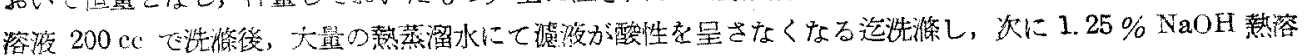

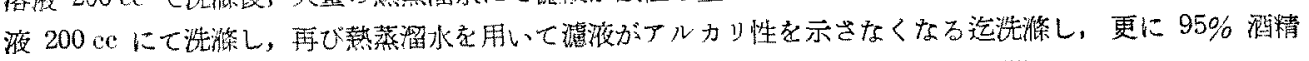

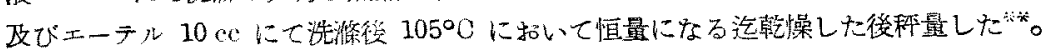

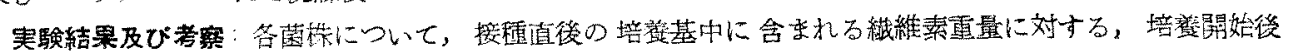

Table. 1. Weight of residual cellulose after deterioration by narine aerobic cellulose-decomposing bacteria for $0,2,5,7,10$ and 20 days. Results are shown in percent.

\begin{tabular}{|c|c|c|c|c|c|c|}
\hline \multirow{2}{*}{$\begin{array}{l}\text { Organiom } \\
\text { inoculated }\end{array}$} & \multicolumn{6}{|c|}{ Incubation time in days } \\
\hline & 0 & 2 & 5 & 7 & 10 & 20 \\
\hline $\begin{array}{c}\text { Cellvibrio flav. } \\
\text { var. marinus }\end{array}$ & 100 & 98.3 & 96.2 & 95.3 & 93.3 & 87.3 \\
\hline Vibrio purpureus & 100 & 98.7 & 98.4 & 96.3 & 95.4 & 90.7 \\
\hline $\begin{array}{l}\text { Vibrio purpurens } \\
\text { var. albus }\end{array}$ & 100 & 99.2 & 98.7 & 98.5 & 97.8 & 96.5 \\
\hline
\end{tabular}

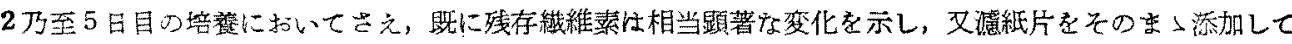

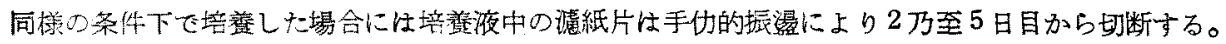

更に Jable1によれば，使用した3菌株のうちては Cellvibrio flavescens var. marinus が最もすみ

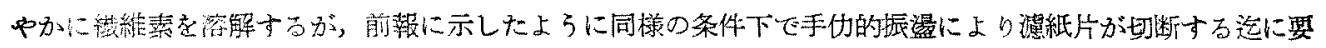

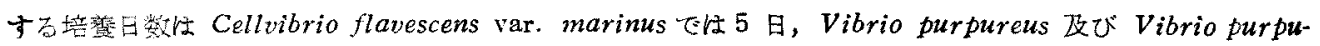

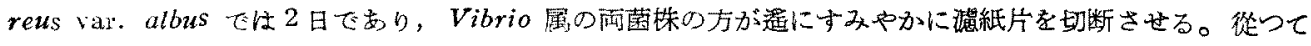

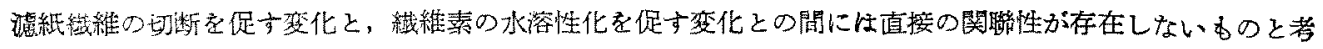

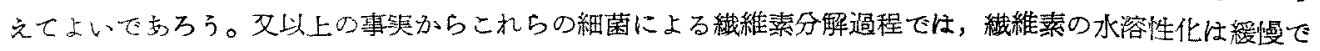

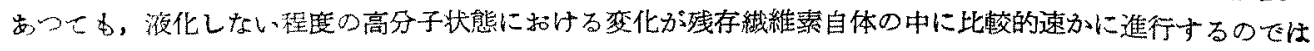

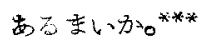

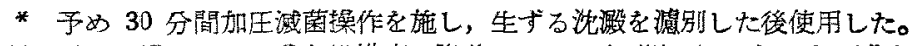

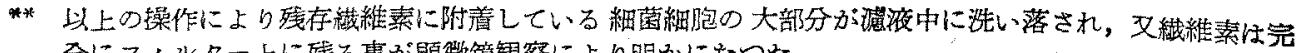
全にフィルター上に残る事が顥微鏡観察により明かになつた。

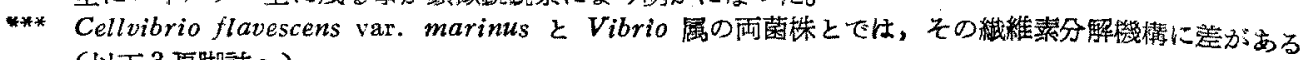
(日下 3 頁脚語へ) 


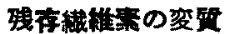

\section{叙上の結果から残存織維素の諸性算の検討㕝試みた。}

残存緎維素の变啠を知る指標として，銅価及び 稀酸分解速度 恒数变化率 2)をえらび，培荃日数の経過に 伴ら,これらの值の变化を测定笅察した。

\section{1. 銅価の変化}

接電菌及び培姜方法: Cellvibrio flavescens var. marinus, Vibrio purbureus 及び Vibrio purbure-

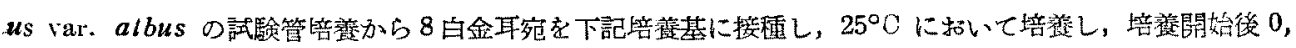
2,5 改び 10 日目に定量老試みた。

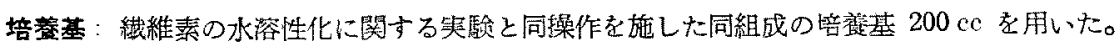

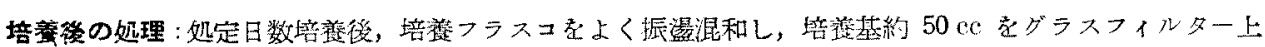

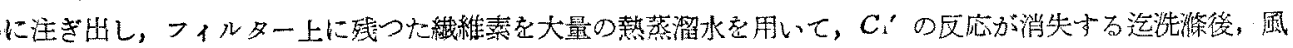
乾して銅牺測定用の試粼とした。

跧洒の測定：前記風乾試料 $0.25 \mathrm{~g}$ について HEYES ${ }^{3)}$ の方法に從つてミク口の槻模に捛 いて測定した。

実験結果及び考察：得られた結棵忹 Table. 2 に示す如くで岗る。但し表中の值住 $105^{\circ} \mathrm{O}$, 3 時間乾懆した試料 $100 \mathrm{~g}$ が消劕する銅量を g で表示したすのである。

Table 2 から明かなよらに、いす゚れの菌株

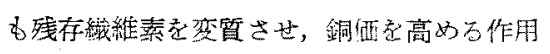
を示すが，培意日数の経過に伴う銅洒の落化

Table 2. Copper number of residual cellulose after deterioration by marine aerohic cellulosedecomposing organisms for $0,2,5$ and 10 dass.

\begin{tabular}{c|c|c|c|c}
\hline \multirow{2}{*}{$\begin{array}{c}\text { Organism } \\
\text { inoculated }\end{array}$} & \multicolumn{3}{|c|}{ Incubation time in days } \\
\cline { 2 - 5 } & 0 & 2 & 5 & 10 \\
\hline $\begin{array}{c}\text { Cellvibrio flav. } \\
\text { var. maririus }\end{array}$ & 1.03 & 1.08 & 1.13 & 1.14 \\
Vibrio pavpurcus & 1.03 & 1.17 & 1.32 & 1.46 \\
$\begin{array}{c}\text { Viorio purpureus } \\
\text { var. albus }\end{array}$ & 1.03 & 1.12 & 1.26 & 1.34 \\
$\begin{array}{c}\text { Control } \\
\text { (uninoculated) }\end{array}$ & 1.03 & 1.03 & 1.03 & 1.03 \\
\hline
\end{tabular}

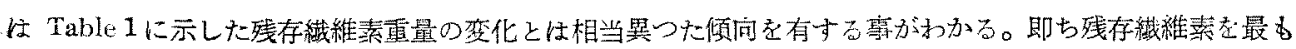

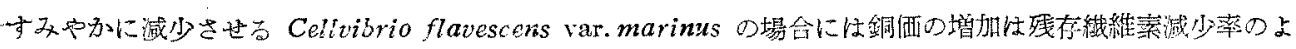

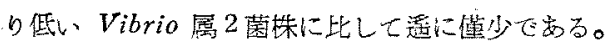

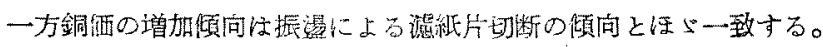

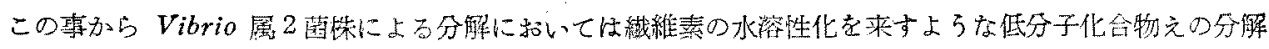

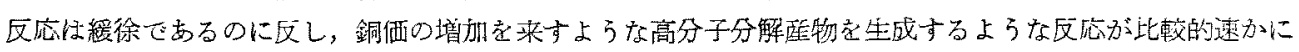
行われ，Cellvibrio flavescens var. marinus の場合にはその反対の傾向があるあのと考えられる。

\section{2. 稀酸分解遗度垣数変化率}

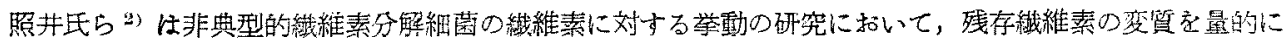

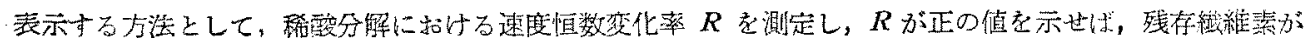
一化学的に脆弱化せる事が指示ざ扎ると述べているが，著者も，同氏の方法に從つて残存絒維素の变啠の指漂

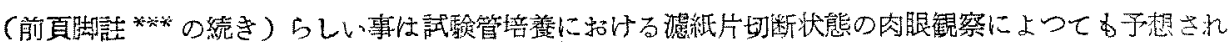

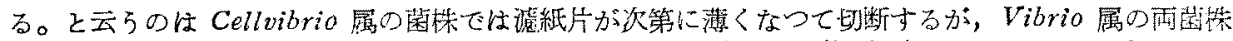

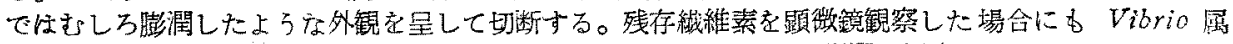

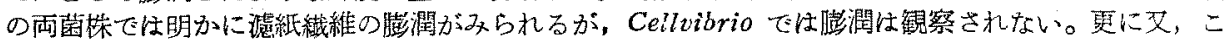
れらの細菌が瀻維素寒天平板”，上に生育した場合，その集落周辺に生成寸る clcar zone の大きさは

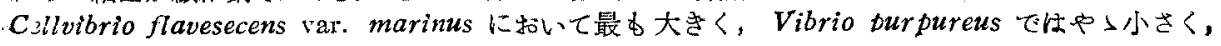
Vibrio purpureus var. albusでは殆ど認められない程度である。 
として $R$ の测定を尌みた。

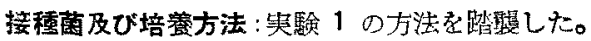

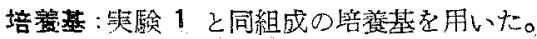

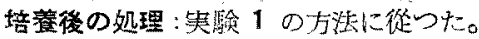

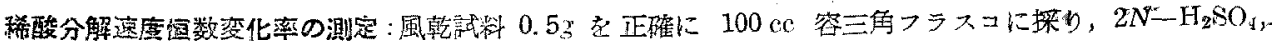

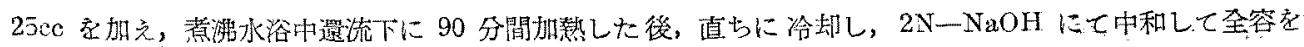

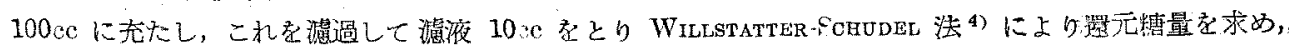

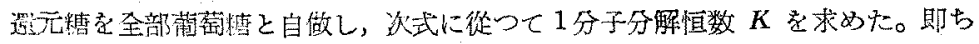

$$
\begin{aligned}
K & =\frac{1}{t} \ln 1-0.9 X \\
& =-\frac{1}{t} \ln (1-0.9 X)
\end{aligned}
$$

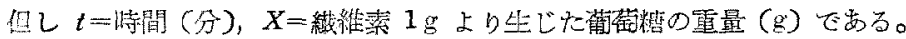

Table 3 Index $(R)$ of residual cellulose aiter deterioration by warine acrobic cellulose-decomposing bacter a for 5,7 and 20 days. Index $(R)$ was defined as follows:

$$
R=\frac{\mathrm{K}-\mathrm{K}_{0}}{\mathrm{~K}_{\mathbf{0}}} \times 100
$$

where $K$ is a velocity constant of hydrolysis of r sidual cellulose with $2 \mathrm{~N}-\mathrm{H}_{2} \mathrm{SO}_{4}$ at $100^{\circ} \mathrm{C}$, and $K_{0}$ is that of intact one in a control.

\begin{tabular}{c|c|c|c}
\hline Organism & \multicolumn{3}{|c}{ Inculation tine in days } \\
\cline { 2 - 4 } inoculated & 5 & 7 & 20 \\
\hline $\begin{array}{c}\text { Cellvibrio flav. } \\
\text { var. marinus }\end{array}$ & 6.8 & 20.1 & 31.6 \\
Vibrio purpureus & 33.4 & 40.2 & 50.7 \\
Vibrio purpureus & 20.1 & 33.4 & 41.0 \\
\hline
\end{tabular}

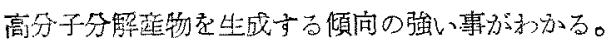

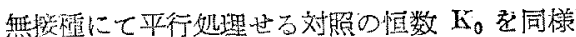
にして求め，次式により恒数梦化率算出した

$$
R=\frac{K-K_{0}}{K_{0}} \times 100
$$

穾唤結喿: Table 3 に示卞如くで要る。

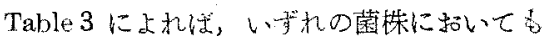

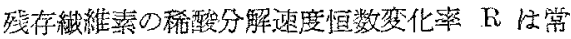

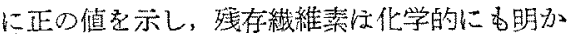

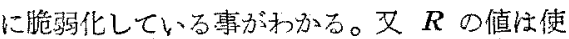
朋した3菌塔のららたは Vibrio purpureus において最む大です Cellvibrio flavescens var. marinus に括いて最杂小さいが，この碩 间的 Table 2 に示した銅価の㑯问とよく一致し。

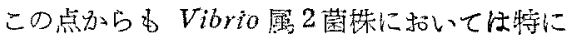

総 括

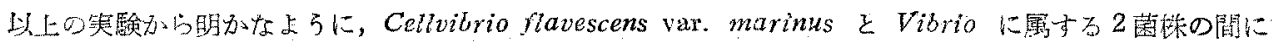

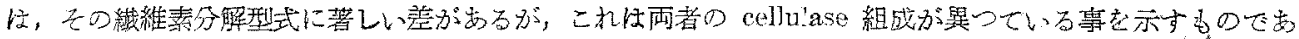

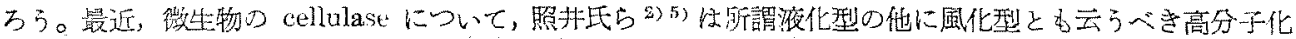

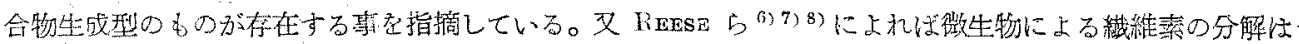

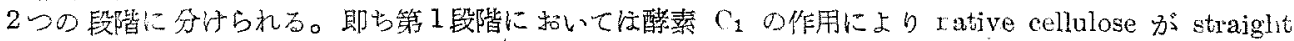

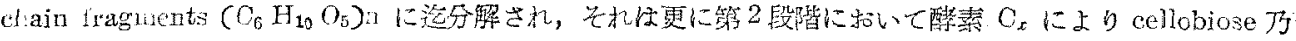

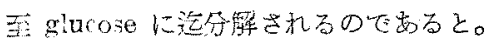

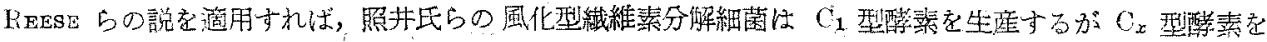

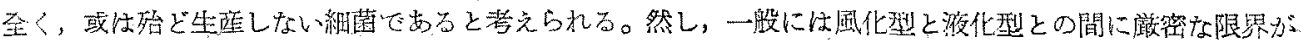

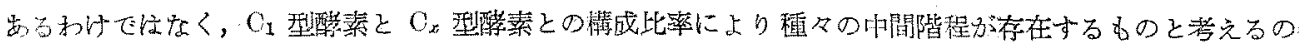
当当索ら弓。

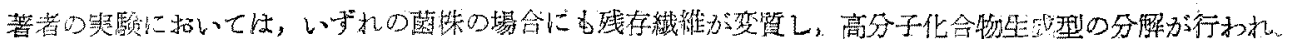




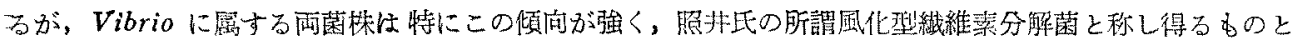

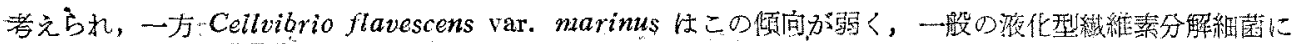
属するるのと思利れる。

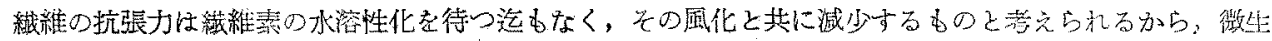

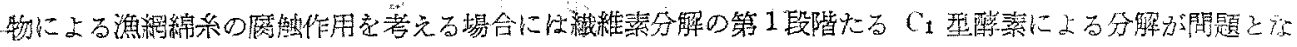

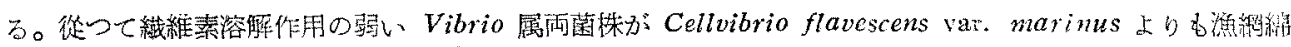

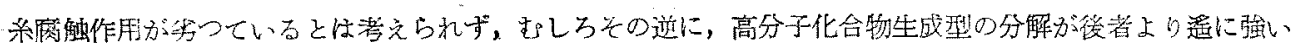

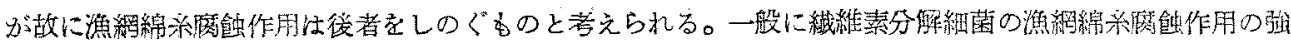

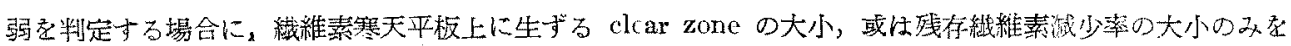
以て，その基準にする事は極めて危除であうう。

要 約

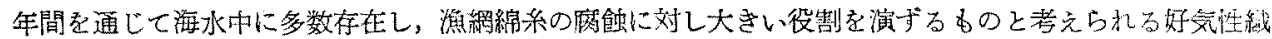
維素分解細菌の弓ち，夏季に多く出現するVibrio purpureus 及びVibrio purtureus va:。 albus，秋，

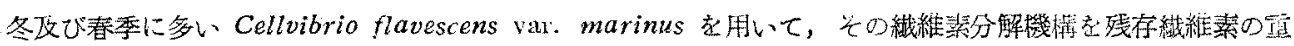

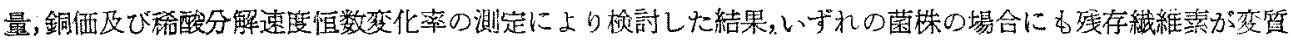

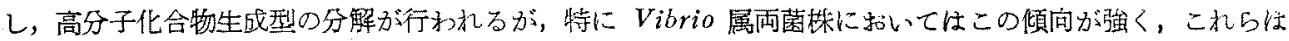
所謂風化型織維素分解細菌に属する事が明かになつた。Cellvibrio flavescens var. marinus に家いてはこ

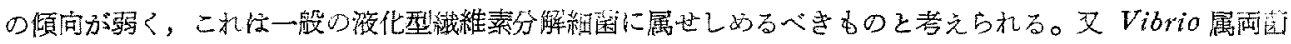

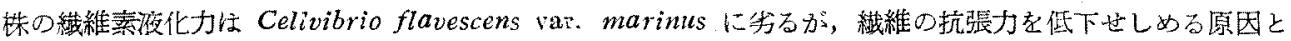

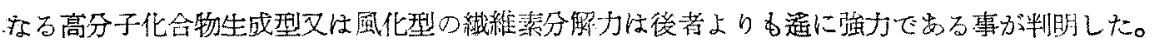

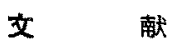

1) 門田:日水誌, 16 (12), 63-70 (1951).

2) 照茾, 藤原 : 酸喏工学誌, 27, 10-15 (1949).

3) Hexes, T. F: Jour. Soc. Chem In.t., 47 (90T) (1928).

4) Wildstätter, R. n. SchUdel, l. : Ber., 51, 780 (1918).

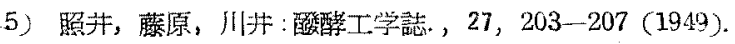

6) Reese, E.T., Sin, R.G., and I.tinson, H.S. : Jour. Bact. 59, 425-497 (1950).

7) I.evinson, H.S., and Reese, E.T. : Jour. Gen. Physiol, 33, 601-628, (1950).

8) Levinson, H.S., Mandels, G.R., and Reese, E.T.:Arch. Biochem. and Biophys. , 31, 351-355, (1951). 